\title{
Establishment of a progesterone-sensitive cell line from human lung cancer
}

\author{
YOSHIO NISHIZAWA ${ }^{1,2}$, MEGUMI YAMASAKI ${ }^{3,4}$, HIROSHI KATAYAMA ${ }^{3,4}$, \\ YOSHIKUNI AMAKATA ${ }^{5}$, SHINJI FUSHIKI ${ }^{1}$ and YASUKO NISHIZAWA ${ }^{3,4}$ \\ ${ }^{1}$ Research Institute for Neurological Diseases and Geriatrics, Kyoto Prefectural University of Medicine, Kyoto 602-0841; \\ ${ }^{2}$ Shiga University of Medical Science, Ohtsu, Shiga 520-2192; ${ }^{3}$ Department of Pathology, Research Institute, \\ Osaka Medical Center for Cancer and Cardiovascular Diseases, 1-3-3 Nakamichi, Higashinari-ku, Osaka 537-8511; \\ ${ }^{4}$ Laboratory of Clinical and Experimental Pathophysiology, Graduate School of Pharmaceutical Science, \\ Osaka University, Suita, Osaka 565-0871; ${ }^{5}$ Suminoe Hospital, Osaka 559-0017, Japan
}

Received February 5, 2007; Accepted May 3, 2007

\begin{abstract}
For deveplopment and function of the lung, progesterone (Prog) fulfils important roles. In a recent report, immunolocalization of Prog and estrogen receptors in nonsmall cell lung carcinomas were examined and it was shown that the Prog receptor might be a potent prognostic factor. In the present study, a cell line with the sensitivity to Prog was established from a human lung cancer and the growth mechanism was analyzed. The proliferation of established SN96-42 cells was sensitive to Prog and antiprogesterone RU38486 inhibited their proliferation stimulated by Prog. Exposure of these cells to Prog resulted in a decreased formation of leukotriene (LT). The 5-lipoxygenase inhibitor (5-LOX), AA861, effectively stimulated SN96-42 cell proliferation and 5-LOX-catalyzed product(s), especially LTC4, inhibited SN96-42 cell proliferation caused by Prog. Prog-sensitive enhancement of SN96-42 cell proliferation is at least partly mediated through an inhibition of LT formation and these data suggest that 5-LOX and LTs play important roles in SN96-42 cell proliferation stimulated by Prog.
\end{abstract}

\section{Introduction}

Hormone-responsive tumors such as breast, endometrial and prostatic cancers are derived from typical hormonal target tissues (breast, uterus and prostate), in which the proliferation and differentiation of target cells are regulated by various factors such as hormones and polypeptide growth factors. Steroid hormones are known to stimulate initiation and/or promotion step of carcinogenesis. Many studies have shown the

Correspondence to: Dr Yasuko Nishizawa, Department of Pathology, Research Institute, Osaka Medical Center for Cancer and Cardiovascular Diseases, 1-3-3 Nakamichi, Higashinari-ku, Osaka 537-8511, Japan

E-mail: nisizawa-ya@mc.pref.osaka.jp

Key words: progesterone, lung cancer, growth, leukotriene roles of steroid hormones in carcinogenesis. Epidemiological work and therapeutic efficacy data of hormone therapy also support the role of estrogen in carcinogenesis.

In order to investigate the action mechanism of estrogen in tumor growth, B-1F cells were established from an estrogensensitive mouse Leydig cell tumor in our laboratory. Inhibitors for 5-lipoxygenase (5-LOX), a key enzyme of leukotriene (LT) synthesis, enhanced the B-1F cell proliferation whereas inhibitors for cyclooxygenase had no marked effect. Estradiol-17ß (E2) stimulated the proliferation and inhibited LT synthesis in B-1F cells and LTs inhibit the proliferation of $\mathrm{B}-1 \mathrm{~F}$ cells (1-7). This indicates that the proliferation of $\mathrm{B}-1 \mathrm{~F}$ cells is largely regulated in a negative manner by LTs whose production is suppressed by estrogen.

Recently, the number of the patients with lung cancer has increased. The major types of lung cancer are squamous cell carcinoma and adenocarcinoma. Squamous cell carcinoma often arises from a central part of the lung, and adenocarcinoma from a peripheral part. Smoking is involved in the generation of squamous cell carcinoma of the lung in many patients. The generation of adenocarcinoma in the lung has not been sufficiently clarified. In the peripheral part of the lung, where the microvasculature richly exists, various functions including gas exchange take place. There seems to be a relationship between drug metabolism and the generation of lung cancer.

Sex steroid hormones such as estrogen and progesterone (Prog) are implicated in numerous developmental and functional processes. For the development and function of the lung, Prog fulfils important roles. Studies on the ontogenetic pattern of Prog and estrogen receptors support the idea that both steroids are important for prenatal lung maturation and development (8). It is well known that sex steroid hormones contribute to the development of hormonedependent carcinomas including breast, endometrial and prostate cancers. However, lung cancer is not generally considered a typical target for sex steroid hormones. In a recent report, immunolocalization of Prog and estrogen receptors in non-small cell lung carcinomas (NSCLCs) were examined and it was shown that the Prog receptor (PR) might be a potent 
prognostic factor (9). In another report, the PR gene was frequently methylated in mouse lung tumor-derived cell lines (10). In the present study, the cell line with the sensitivity to Prog was established from the human lung cancer developed in a patient during the treatment of bronchial asthma and their growth mechanism was analyzed. Especially, the relationship between leukotriene synthesis and proliferation of the established cell was examined, because leukotrienes have crucial roles in some lung diseases, for example in bronchial asthma.

\section{Materials and methods}

Cell culture. Dissected squamous cell carcinoma tissue from a patient with lung cancer was used to establish the cloned cells. The patient was treated for bronchial asthma with various antiasthmatic drugs. Our research was started after obtaining informed consent from the patient and his family. The fundamental methods for preparing the dispersed cells from the solid tumor and isolating cytokeratin-positive cells were previously reported (11). The cells were subcultured weekly in Eagle's minimum essential medium (MEM) containing FBS (10\%) and $10^{-8} \mathrm{M}$ Prog. The cultured cells in their 50th passage were cloned by limiting dilution. More than 25 clones were examined to select the clonal cells that showed Prog-responsive proliferation in serum-free medium: Ham's F12-MEM (1:1, vol./vol.) containing 0.1\% (wt/vol.) BSA (HMB). One was termed SN96-42. SN96-42 cells used in the present experiments were found to proliferate well in the medium without any aid from exogenous peptide hormones or attaching factors and kept in a humidified atmosphere in the presence of $5 \% \mathrm{CO}_{2}-95 \%$ air. Cells grown to confluence were transferred with the use of trypsin solution: trypsin $(0.01 \%$, $\mathrm{wt} / \mathrm{vol}$.)-EDTA $(0.02 \%$, wt/vol.) in phosphate buffered saline (PBS).

Cell proliferation experiments in culture. The effects of test compounds on the cell yield or DNA synthesis were examined with slight modification as previously published $(3,7,12)$. SN96-42 cells were plated into four replicate $35-\mathrm{mm}$ dishes at an initial density of $1 \times 10^{4}$ cells/dish in $2 \mathrm{ml}$ of HMB medium. On the following day (day 0 ), the medium was replaced by $2 \mathrm{ml}$ of serum-free HMB with or without test compounds, unless specified otherwise. The medium was changed every other day. When LTs were used as test compounds, the culture media were changed every day due to their instability as previously described $(3,7)$. At the indicated times, cells were harvested with trypsin solution and counted with a hemocytometer using the trypan blue dye exclusion method on day 6, unless otherwise specified. $\left[{ }^{3} \mathrm{H}\right]$-thymidine incorporation assay was also performed as previously described. SN96-42 cells were plated onto a 96-well plate at an initial density of $2 \times 10^{3}$ cells/well in $0.15 \mathrm{ml}$ of HMB medium and on the following day (day 0 ), the medium was replaced by $0.15 \mathrm{ml}$ of HMB medium with or without test compounds. On day 3 , the cells were pulsed with $\left[{ }^{3} \mathrm{H}\right]$-thymidine $(0.15 \mu \mathrm{Ci} / 0.15 \mathrm{ml} /$ well $)$ for $2 \mathrm{~h}$ at $37^{\circ} \mathrm{C}$ in a humidified incubator. The radioactivity (DPM) incorporated into the cells, which were briefly trypsinized and collected with a Cell Harvester LM 101 (Lab Science, Tokyo, Japan), was measured.
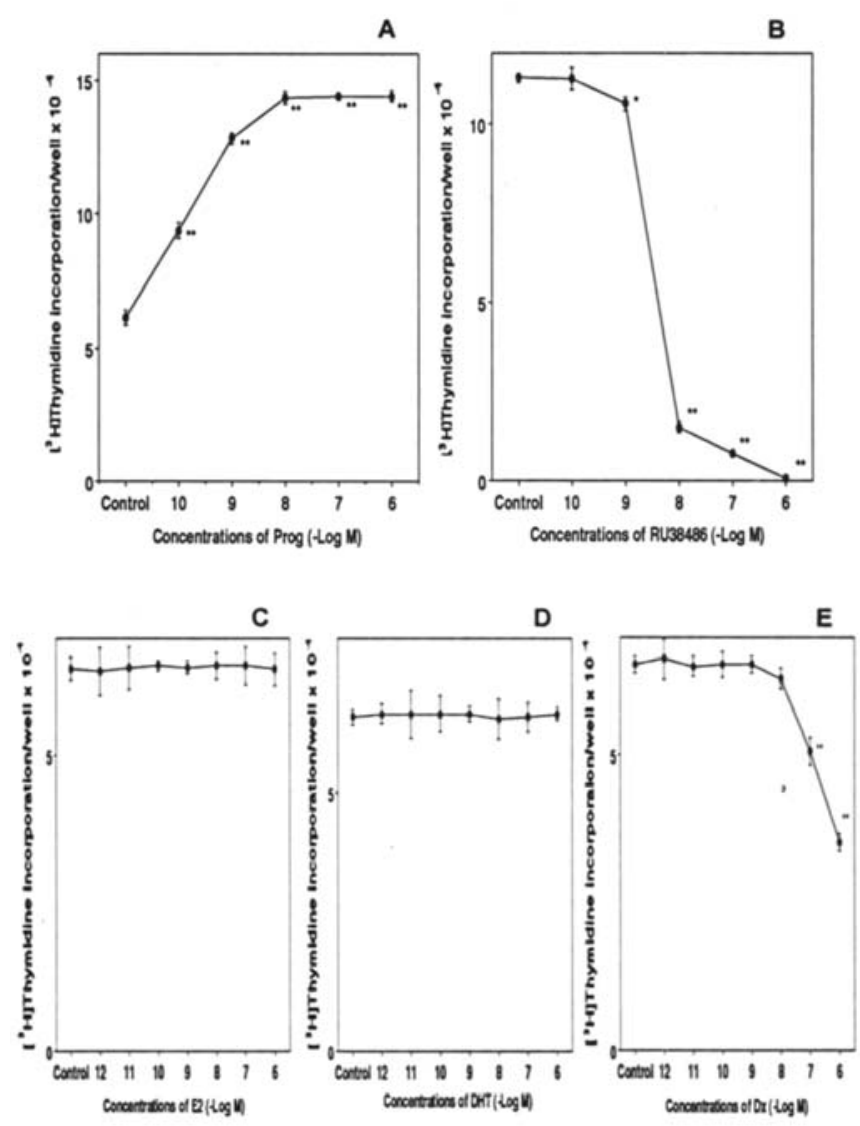

Figure 1. Effects of various concentrations of Prog, RU38486, E2, DHT or Dx on DNA synthesis in SN96-42 cells. SN96-42 cells were cultured with various concentrations of Prog (A), E2 (C), DHT (D) or Dx (E). The effects of increasing concentrations of RU38486 on SN96-42 cell proliferation stimulated with $10^{-8} \mathrm{M}$ Prog were also examined (B). The radioactivity (DPM/well) of $\left[{ }^{3} \mathrm{H}\right]$-thymidine incorporated into the cells was measured as described in Materials and methods. Points, means of 4 determinations; bars, $\mathrm{SE} ;\left(^{* *}\right) \mathrm{p}<0.01 ;\left(^{*}\right) \mathrm{p}<0.05$. The other 3 trials gave similar results.

Binding analysis of progesterone receptor. The whole cell binding assay was used to obtain the binding parameters of PR in SN96-42 cells as previously described (2,5,12-14). The cells were washed four times with MEM containing $5 \mathrm{mM}$ HEPES (4-(2-hydroxyethyl)-1-piperazineethanesulfonic acid) and $0.1 \%$ (wt/vol) BSA before determining the radioactivity specifically associated with the cells. The amount of $\left[{ }^{3} \mathrm{H}\right]-$ Prog specifically bound to the cells was determined as previously reported (11). The specific binding was analyzed according to the Scatchard method (15). To examine binding specificity, the cells were incubated with $2 \times 10^{-9} \mathrm{M}\left[{ }^{3} \mathrm{H}\right]-\mathrm{Prog}$ in the presence of various concentrations of Prog, estradiol (E2), dihydrotestosterone (DHT) or dexamethasone (Dx) at $37^{\circ} \mathrm{C}$ for $60 \mathrm{~min}$ and treated as described above.

Immunohistochemistry. For the immunohistochemistry, $3 \mu \mathrm{m}$ thick sections were cut from the formalin-fixed, paraffinembedded blocks of the original tumor. Slides were incubated for $5-10$ min in $0.3 \%$ hydrogen peroxide in methanol to quench endogenous peroxidase activity and washed twice in PBS for 5 min each. For antigen retrieval before the immunostaining, slides were immersed in a container with citrate buffer, $\mathrm{pH}$ 6.0, 

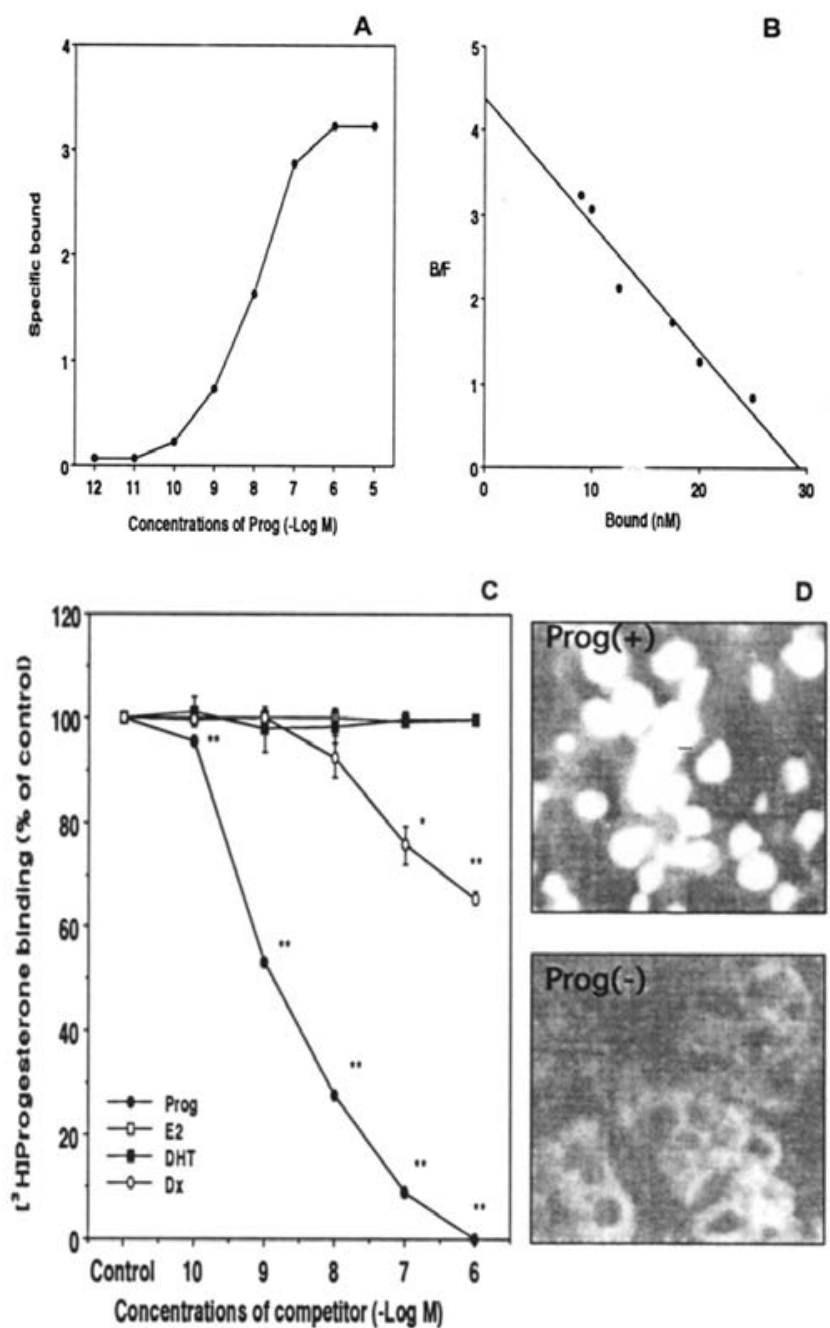

Figure 2. Characterization of PR in SN96-42 cells. SN96-42 cells were harvested and then incubated with various concentrations of $\left[{ }^{3} \mathrm{H}\right]-\operatorname{Prog}$ in the presence or absence of 100 -fold excess nonradioactive Prog at $37^{\circ} \mathrm{C}$ for 60 min. Saturation curve is shown in A. The amount of $\left[{ }^{3} \mathrm{H}\right]-$ Prog specifically bound to SN96-42 cells was analyzed by a Scatchard plot (B). C, SN96-42 cells were incubated with $2 \times 10^{-9} \mathrm{M}\left[{ }^{3} \mathrm{H}\right]$-Prog in the presence or absence of increasing concentrations of nonradioactive Prog, E2, DHT or Dx. The radioactivity bound to SN96-42 cells was determined. Binding is expressed as a percentage, taking the values of $\left[{ }^{3} \mathrm{H}\right]$-Prog bound without nonradioactive ligand as $100 \%$. Points in $\mathrm{A}$ and $\mathrm{B}$, means of 2 determinations; points in $\mathrm{C}$, means of 3 determinations; bars in $\mathrm{C}, \mathrm{SE} ;\left(^{* *}\right) \mathrm{p}<0.01 ;\left(^{*}\right) \mathrm{p}<0.05$. A further 3 trials gave similar results. In $\mathrm{D}$, immunofluorescence cell staining with antibody for PR shows the nuclear immunoreactivity in SN96-42 cells treated with Prog

microwaved for $15 \mathrm{~min}(600 \mathrm{~W}, 5 \mathrm{~min}$, three times) and then cooled for about $30 \mathrm{~min}$ before rinsing. Slides were incubated for $30 \mathrm{~min}$ with $2 \%$ normal goat serum in $0.1 \%$ Tween-20PBS. After removing blocking serum, slides were incubated with primary antibody (200-folds dilution) for PR overnight at $4^{\circ} \mathrm{C}$. On the following day, slides were washed three times for 5 min each with $0.1 \%$ Tween-20-PBS buffer, incubated with Envision $^{\mathrm{TM}}+$ Peroxidase (mouse) as directed in the manual from the supplier and observed by a light microscopy. For the negative control, the primary antibody was replaced with an isotype-matched negative control antibody (Dako), which showed no specific reactivity. In another experiment SN96-42

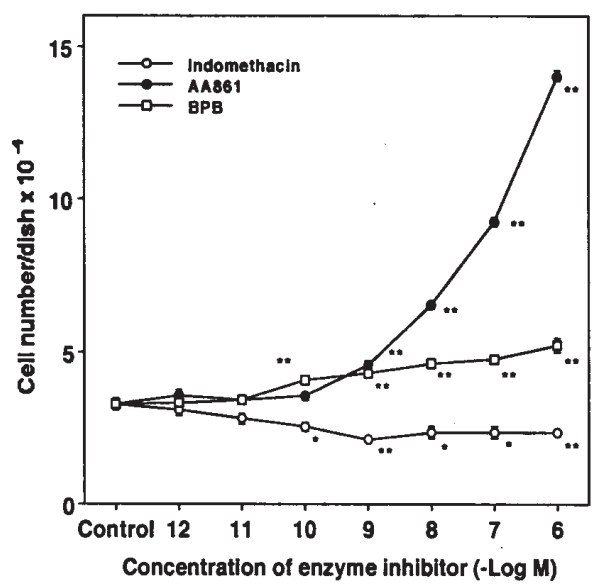

Figure 3. Effects of 5-lipoxygenase, phospholipase A2 or cyclooxygenase inhibitor on SN96-42 cell proliferation. SN96-42 cells plated into 35-mm dishes were cultured in $2 \mathrm{ml} \mathrm{HMB}$ with various concentrations of test compounds in the absence of Prog. The viable cells were counted on day 6 . Points, means of 4 determinations; bars, SE; $\left(^{* *}\right) \mathrm{p}<0.01 ;\left(^{*}\right) \mathrm{p}<0.05$. The other 3 trials gave similar results.

cells were plated on a sterile four well-chamber slide (Falcon) at a density of $2 \times 10^{4}$ cells/well in MEM containing $10 \%$ DCCtreated FBS. On the following day (day 0), the medium was changed to HMB medium with or without $10^{-8} \mathrm{M}$ Prog. On Day 2 the cells were fixed in $4 \%$ paraformaldehyde for $10 \mathrm{~min}$ and washed in three changes of PBS. Omitting the step involving treatment of the cells with hydrogen peroxide, immunofluorescence cell staining was performed with Alexa Fluor 448-labeled goat anti-mouse antibody as directed in the manual from the supplier.

Leukotriene assay. The contents of various leukotrienes in SN96-42 cells and their conditioned medium were examined as previously described (7).

Statistics. The data were expressed as mean \pm standard error (SE). Data were analyzed by ANOVA with Dunnett or Bonferroni's corrections for multiple comparisons, as appropriate. The p-values of $<0.05$ and 0.01 were considered to be significant and highly significant, respectively.

Materials. Materials were obtained from the following sources: BSA (crystallized and lyophilized bovine serum albumin), radioinert Prog and trypsin from Sigma Chemical Co. (St. Louis, MO); Eagle's minimum essential medium and Ham's F12 from Nissui Pharmaceutical Co., Ltd. (Tokyo, Japan $) ;\left(5,6,8,9,11,12,14,15-{ }^{3} \mathrm{H}\right)$ arachidonic acid $(60-100 \mathrm{Ci} /$ mmol), LTB4 or LTC4 [ $\left.{ }^{3} \mathrm{H}\right]-R I A ~ k i t s, ~\left(1,2,6,7-{ }^{3} \mathrm{H}\right)$ Prog $(80-$ $110 \mathrm{Ci} / \mathrm{mmol}$ ) and (methyl-1',2'-3 $\mathrm{H})$ thymidine $(40-100 \mathrm{Ci} /$ mmol) from DuPont/NEN Research Products (Wilmington, DE). The materials for HPLC from Waters Associates (Bedford, MA). Unlabeled LTs were purchased from Cayman Chemical Co., Inc. (Ann Arbor, MI). Monoclonal antibody (PgR636) for PR and Envision ${ }^{\mathrm{TM}}+$ Peroxidase (mouse) were purchased from Dako Co. (Carpinteria, CA). Alexa Fluor 448-labeled goat anti-mouse antibody was purchased from Molecular Probes Inc. (Eugene, OR). The other reagents used were of analytical grade. 

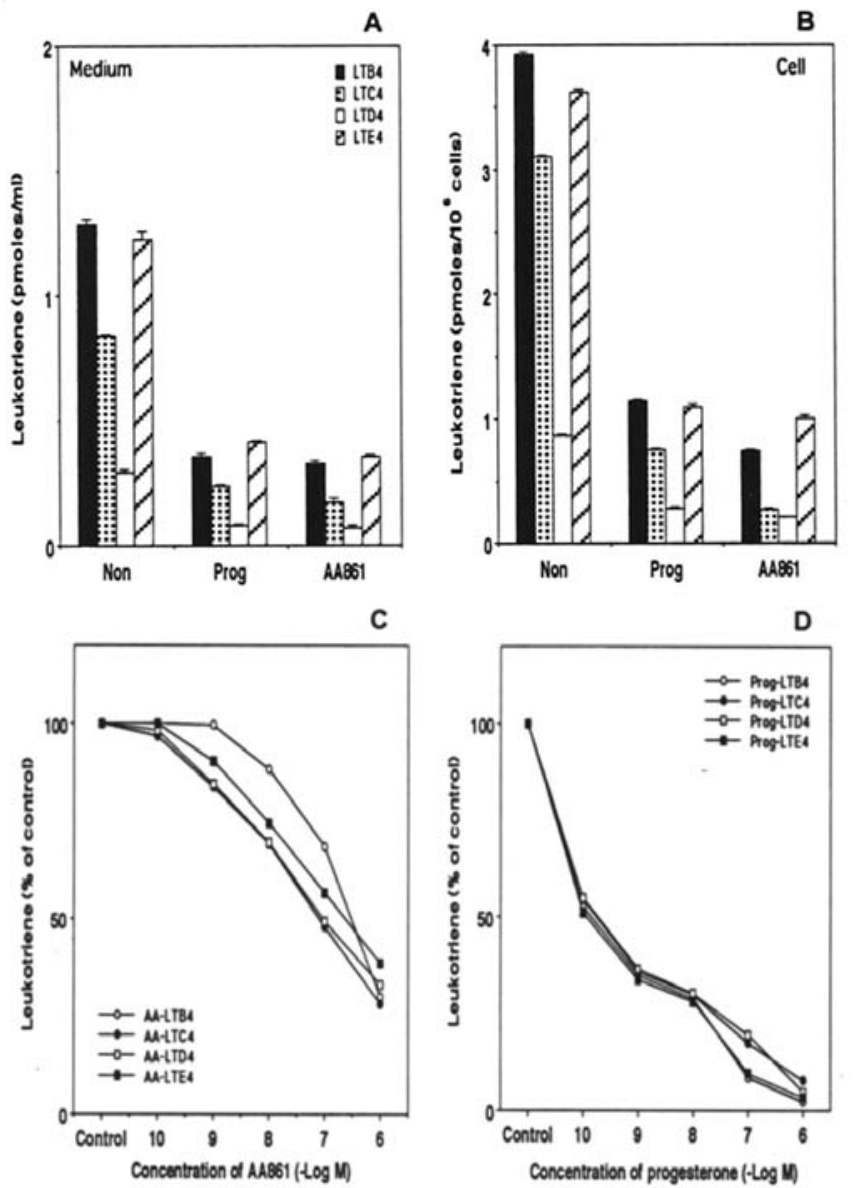

Figure 4. Effects of AA861 or Prog on LT content. SN96-42 cells were plated in an HMB medium at a cell density of $10^{6} / 60-\mathrm{mm}$ dish. After culture for $24 \mathrm{~h}$, cells were treated without or with $10^{-8} \mathrm{M}$ Prog or $10^{-6} \mathrm{M}$ AA861 for $48 \mathrm{~h}$ and then replaced with a fresh medium containing the same compounds. These cells were subjected to further treatments for $7 \mathrm{~h}$. LT content in the medium (A) or cells (B) was determined as described in Materials and methods. The data (mean $\pm \mathrm{SE}$ ) were obtained by five replicate assays. Cells were also treated with various concentrations of AA861 (AA) (C) or Prog (D) and LT content in the medium was determined. The values (percentage of control) represent means of five replicate assays, taking the contents of LTs produced without AA861 or Prog as $100 \%$. The other 2 trials gave similar results.

\section{Results}

Effects of Prog or antiprogesterone on the growth of SN96-42 cells. Prog was found to stimulate the growth of SN96-42 cells in a concentration-dependent manner (Fig. 1A), the maximum effect being at a range of $10^{-9}-10^{-8} \mathrm{M}$. In the following studies, Prog at $10^{-8} \mathrm{M}$ was used in order to obtain a maximum and reproducible growth-stimulative effect, unless specified otherwise. The addition of RU38486 with $10^{-8} \mathrm{M}$ Prog into a serum-free medium resulted in a decreased cell growth (Fig. 1B). RU38486 was used as the antiprogesterone in the following experiments owing to its potent growth-inhibitory ability. E2 and DHT had no significant effect on SN96-42 cell proliferation, while Dx inhibited SN96-42 cell proliferation at a higher concentration (Fig. 1C, D and E).

$P R$ in SN96-42 cells. Scatchard analysis of the specifically bound $\left[{ }^{3} \mathrm{H}\right]-$ Prog to whole cells suggested the presence of

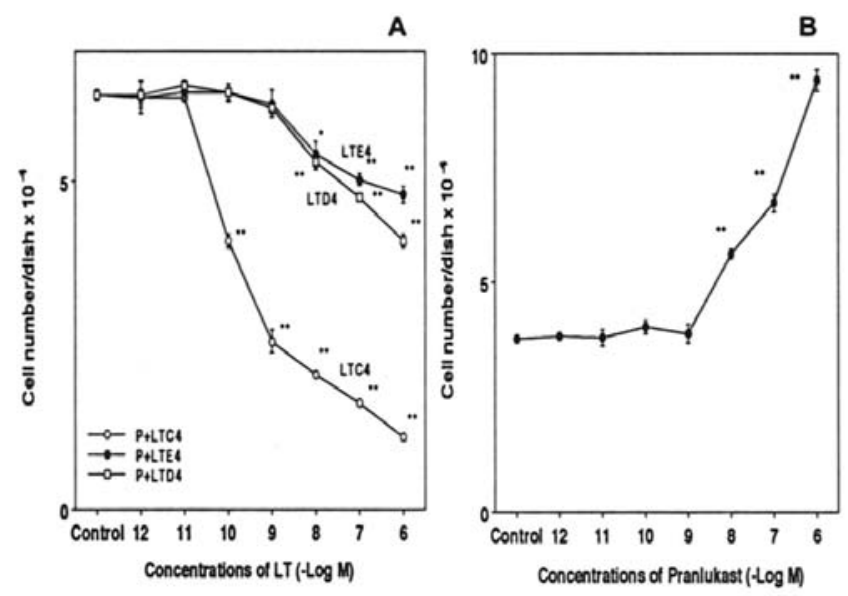

Figure 5. Inhibitory effect of peptidyl LTs on the proliferation of SN96-42 cells. SN96-42 cells plated into 35-mm dishes were cultured in $2 \mathrm{ml} \mathrm{HMB}$ with various concentrations of LTs in the presence of $10^{-8} \mathrm{M}$ Prog (P) (A). In another experiment SN96-42 cells were cultured with various concentrations of LTC4/D4/E4 antagonist pranlukast in the presence of both $10^{-8} \mathrm{M}$ Prog and $10^{-8} \mathrm{M}$ LTC4 (B). The viable cells were counted on day 6 . Points, means of 4 determinations; bars, SE; $\left(^{* *}\right) \mathrm{p}<0.01 ;\left(^{*}\right) \mathrm{p}<0.05$. The other 3 trials gave similar results.

high affinity binding sites (Fig. 2A, 2B). The dissociation constant of $\left[{ }^{3} \mathrm{H}\right]-$ Prog binding sites was $0.5-1 \times 10^{-8} \mathrm{M}$, similar to that of authentic PR. To confirm the presence of PR in SN96-42 cells, the steroid specificity of the binding components was then investigated (Fig. 2C). The experiments using $\left[{ }^{3} \mathrm{H}\right]$-Prog as a radioactive ligand were conducted. PR binding was found to be specific for Prog. Dx competed to a lesser degree than Prog, while unlabeled E2 or DHT did not compete for $\left[{ }^{3} \mathrm{H}\right]-$ Prog binding even at $\mu \mathrm{M}$ concentrations. The presence of PR was also confirmed by immuno-staining. The nuclear PR immunoreactivity (Alexa Fluor 448) was observed in SN96-42 cells (Fig. 2D) cultured in the medium with Prog as well as the original tumor (data not shown) from which SN96-42 cells were derived.

Effects of enzyme inhibitors in arachidonic acid metabolic pathways on SN96-42 cell proliferation. Several enzyme inhibitors in arachidonic acid metabolic pathways were incubated with SN96-42 cells in the absence of Prog. As shown in Fig. 3, an addition of 2-(12-hydroxydodeca-5,10-diynyl)3,5,6-trimethyl-1,4-benzoquinone (AA861) to the HMB medium resulted in a dose-dependent increase in cell yield at a range of $10^{-9}$ to $10^{-6} \mathrm{M}$. The PLA2 inhibitor, p-bromophenacyl bromide (BPB) was examined for its effect on the proliferation. While BPB was much less potent than AA861, it showed stimulatory activity. The cyclooxygenase inhibitor, indomethacin did not elicit a significant stimulatory effect on SN96-42 cell proliferation at a range of $10^{-9}$ to $10^{-6} \mathrm{M}$, and it showed a slight inhibitory effect.

Effects of Prog on LT formation. The effects of Prog and AA861 on the contents of various LTs in SN96-42 cells and their conditioned medium were evaluated (Fig. 4). Both AA861 and Prog decreased the contents of LTs in a dosedependent manner (Fig. 4). 
Inhibitory effects of LTs on cell proliferation. In order to confirm the role of LTs in Prog-responsive growth of SN96-42 cells, various concentrations of LTs were added to the culture medium and cell proliferation was examined after 6 days. As shown in Fig. 5A, the increasing concentrations of LTC4 resulted in a significant inhibition of cell yields of Progtreated SN96-42 cells. LTD4 and LTE4 were less potent than LTC4. Inhibition of the cell proliferation with LTC4 was restored after treatment with LTC4/D4/E4 antagonist pranlukast (Fig. 5B).

\section{Discussion}

The proliferation of established SN96-42 cells was sensitive to Prog and antiprogesterone RU38486 inhibited their proliferation stimulated by Prog. Exposure of these cells to Prog resulted in a decreased formation of LTs. Clara cell 10-kD protein (cc10-kD), a secretory phosholipase A2 inhibitor, is suggested to be the human counterpart of rabbit uteroglobin (UG), that is regulated by progesterone and is similar to lipocortin I $(16,17)$. Human cc10-kD is expressed constitutively at a very high level in the human respiratory epithelium (18). In addition to the lung and trachea, cc10-kD-specific transcripts are present in high levels in several nonrespiratory organs and tissues (prostate, thyroid, mammary gland and pituitary), with a distribution pattern very similar, if not identical, to that of UG in the rabbit using the PCR amplification method (18). In the study using an antibody for rabbit UG, a UG-like immuno-reactivity is observed in human endometrium (19), prostate (20) and respiratory tract (21). In our experiments, at first, it was thought that one possible action site of Prog was PLA2. However, Prog did not have a significant effect on the formation of prostaglandins (data not shown) and lowered all four LTs (LTB4, LTC4, LTD4 and LTE4). Five-lipoxygenase inhibitor, AA861, effectively stimulated SN96-42 cell proliferation and 5-lipoxygenase-catalyzed product(s), especially LTC4, inhibited their proliferation. Therefore, Progsensitive enhancement of SN96-42 cell proliferation is at least partly mediated through an inhibition of LT formation. Although the mechanism by which Prog suppresses LT formation remains uncertain, the most probable action site of Prog is 5-lipoxygenase. The addition of antiprogesterone to the Prog-stimulated cells restored LT formation to nearly that of the control (data not shown), indicating that Prog-sensitive inhibition of LT synthesis lies in a PR-mediated process.

Our previous reports suggest the important role of 5-LOX in estrogen-responsive growth enhancement of B-1F cells, established from a mouse estrogen-responsive Leydig cell tumor. The exogenous addition of LTs in the cultured medium led to a reduction of the proliferation and induced apoptosis of B-1F cells (7). It is considered that the inhibition of LT production by estrogen resulted in an enhancement of B$1 F$ cell proliferation. Present results together with these reports show that 5-LOX and LTs play an important role in SN96-42 cell proliferation stimulated by Prog as well as in B-1F cell proliferation stimulated by E2. Although the 5-LOX promoter contains multiple regulatory elements (E2F, Pax-4, USF), no progesterone-responsive element (PRE)-related sequence has been identified in or proximal to the 5-LOX promoter. Therefore, mechanism of decrease of the 5-LOX activity by Prog in SN96-42 cells is not clear. In addition, our present results do not fully agree with other reports in which the proliferation of the tumor cell has decreased by the inhibition of 5-LOX (22-24). It is uncertain why there are differences in the growth response. Recently, it has been reported that medroxyprogesterone acetate induces cell proliferation through up-regulation of cyclin D1 expression via phosphatidylinositol 3-kinase/Akt/nuclear factor- $\kappa$ B cascade in human breast cancer cells (25). Further study is necessary to elucidate the mechanisms of cell growth regulation by Prog.

\section{Acknowledgements}

The technical assistance of Ms. T. Murashima is gratefully acknowledged.

\section{References}

1. Nishizawa Y, Nishii K, Kishimoto S, Matsumoto K and Sato B: Regulatory role of arachidonic acid-derived matabolites for proliferation of transformed murine Leydig cell in serum-free culture condition. Anticancer Res 10: 317-322, 1990.

2. Nishizawa Y, Nishii K, Nishizawa Y, Koga M, Kishimoto S, Matsumoto K and Sato B: Effects of estrogen on cell proliferation and leukotriene formation in tansformed mouse Leydig cells cultured under serum-free conditions. Cancer Res 50: 3866-3871, 1990.

3. Nishii K, Nishizawa Y, Nishizawa Y, Matsumoto K and Sato B: Inhibition of murine transformed Leydig cell proliferation by leukotrienes in serum-free culture. Cancer Res 51: 5573-5578, 1991.

4. Nishizawa Y, Yamamoto T, Taniguchi H and Sato B: Effects of estrogen and leukotrienes on anchorage-independent growth of transformed mouse Leydig cells under serum-free condition. Steroid Biochem (Life Sci Adv) 11: 23-28, 1992.

5. Nishizawa Y, Nishizawa Y, Yamamoto T, Terada N, Amakata Y, Matsumoto K and Sato B: Progression of mouse transformed Leydig cells from estrogen-sensitive to estrogen-insensitive growth phenotype concomitant with loss of leukotriene D4 receptor. Int J Oncol 5: 1077-1084, 1994.

6. Nishizawa Y, Yamamoto T, Terada N, Fushiki S, Amakata Y and Nishizawa Y: Effects of antiallergic drugs on the proliferation of estrogen-sensitive mouse Leydig cell line. Anticancer Res 16: 1241-1246, 1996.

7. Goto HG, Nishizawa Y, Katayama H, Murashima T, Yamasaki M, Tanigaki Y, Kimura S, Fushiki S and Nishizawa Y: Induction of apoptosis in an estrogen-responsive mouse Leydig tumor cell by leukotriene. Oncol Rep 17: 225-232, 2007.

8. Beyer C, Kuppers E, Karolczak M and Trotter A: Ontogenetic expression of estrogen and progesterone receptors in the mouse lung. Biol Neonate 84: 59-63, 2003

9. Ishibashi H, Suzuki T, Suzuki S, Niikawa H, Lu L, Miki Y, Moriya T, Hayashi S, Handa M, Kondo T and Sasano H: Progesterone receptor in non-small cell lung cancer-a potent prognostic factor and possible target for endocrine therapy. Cancer Res 65: 6450-6458, 2005 .

10. Vuillemenot B, Hutt J and Belinsky S: Gene promoter hypermethylation in mouse lung tumors. Mol Cancer Res 4: 267-273, 2006.

11. Sato B, Miyashita Y, Maeda Y, Noma K, Kishimoto S and Matsumoto K: Effects of estrogen and vanadate on proliferation of newly established transformed mouse Leydig cell line in vitro. Endocrinology 120: 1112-1120, 1987.

12. Nishizawa Y, Sato B, Miyashita Y, Tsukada S, Hirose T, Kishimoto $\mathrm{S}$ and Matsumoto $\mathrm{K}$ : Autocrine regulation of cell proliferation by estradiol and hydroxytamoxifen of transformed mouse Leydig cells in serum-free culture. Endocrinology 122: 227-235, 1988 .

13. Nishizawa Y, Sato B, Nishii K, Kishimoto S and Matsumoto K: Effect of androgen on proliferation of estrogen-responsive transformed mouse Leydig cells in serum-free culture. Cancer Res 49: 1377-1382, 1989.

14. Lu J, Nishizawa Y, Tanaka A, Nonomura N, Yamanishi H, Uchida N, Sato B and Matsumoto K: Inhibitory effect of antibody against basic fibroblast growth factor on androgenor glucocorticoid-induced growth of Shionogi carcinoma 115 cells in serum-free culture. Cancer Res 49: 4963-4967, 1989. 
15. Scatchard G: The attraction of proteins for small molecules and ions. Ann NY Acad Sci 51: 660-672, 1949.

16. Miele L, Cordella-Miele E, Facchiano A and Mukherjee A: Novel anti-inflammatory peptides from the region of highest similarity between uteroglobin and lipocortin I. Nature 335: 726-730, 1988.

17. Singh G and Katyal S: Clara cells and Clara cell $10-\mathrm{kD}$ protein (CC10). Am J Respir Cell Mol Biol 17: 141-143, 1997.

18. Peri A, Cordella-Miele E, Miele L and Mukherjee AB: Tissuespecific expression of the gene coding for human Clara cell $10-\mathrm{kD}$ protein, a phospholipase A2-inhibitor protein. J Clin Invest 92: 2099-2109, 1993.

19. Kikukawa T, Cowan B, Tejada R and Mukherjee A: Partial characterization of a uteroglobin-like protein in the human uterus and its temporal relationship to prostaglandin levels in this organ. J Clin Endocrinol Metab 67: 315-321, 1988.

20. Manyak M, Kikukawa T and Mukherjee A: Expression of a uteroglobin-like protein in human prostate. J Urol 140: 176-182, 1988.

21. Dhanireddy R, Kikukawa T and Mukherje A: Detection of a rabbit uteroglobin-like protein in human neonatal tracheobronchial washings. Biochem Biophys Res Commun 152: 14471454,1988
22. Avis I, Hong SH, Martinez A, Moody T, Choi YH, Trepel J, Das R, Jett M and Mulshine JL: Five-lipoxygenase inhibitors can mediate apoptosis in human breast cancer cell lines through complex eicosanoid interactions. FASEB J 15: 2007-2009, 2001.

23. Buckman D, Hubbard N and Erickson K: Eicosanoids and linoleate-enhanced growth of mouse mammary tumor cells. Prostaglandins Leukot Essent Fatty Acids 44: 177-184, 1991.

24. Rioux $\mathrm{N}$ and Castonguay A: Inhibitors of lipoxygenase: a new class of cancer chemopreventive agents. Carcinogenesis 19: 1393-1400, 1998.

25. Saitoh M, Ohmichi M, Takahashi K, Kawagoe J, Ohta T, Doshida M, Takahashi T, Igarashi H, Mori-Abe A, Du B, Tsutsumi S and Kurachi H: Medroxyprogesterone acetate induces cell proliferation through up-regulation of cyclin D1 expression via phosphatidylinositol 3-kinase/Akt/nuclear factorkappaB cascade in human breast cancer cells. Endocrinology 146: 4917-4925, 2005. 